\title{
Wound infection following surgery in an accident and emergency theatre
}

\author{
R. A. J. SPENCE AND W. H. RUTHERFORD \\ Accident and Emergency Department, Royal Victoria Hospital, Belfast
}

\section{SUMMARY}

Five hundred and six clean minor surgical procedures were carried out in an emergency theatre. One theatre was used for both clean and septic conditions; clean cases preceding the septic lesions. Sepsis rates were assessed prospectively and complete follow-up was obtained in 491 patients. Four hundred and fifty $(91.6 \%)$ patients achieved primary healing. Thirty $(6 \cdot 1 \%)$ patients developed a mild serous discharge; three developed wound haematomas and eight $(1.6 \%)$ patients had severely infected wounds with a purulent discharge. From the acceptably low incidence of severely infected wounds we conclude that there is no need for separate clean and septic theatres in an emergency department provided the clean operations are comparatively short and simple procedures.

\section{INTRODUCTION}

There have been many studies on wound infections following inpatient surgical procedures (Cruse, 1973; Ljungqvist \& Lund, 1964; Davis et al., 1973; Leissner, 1976) but sepsis after minor surgery has rarely been investigated (Purssey, 1970). The surgery performed in accident and emergency departments in the UK is usually minor. The debridement and suture of wounds are usually carried out in examination/treatment cubicles. Operating theatres are used for treating abscesses and other septic conditions as well as for a number of minor 'clean procedures'. Many departments, including ourselves only use one operating theatre for this mixed work load. We have assessed our sepsis rate prospectively to see whether this arrangement is acceptable.

Correspondence: $M r W . H$. Rutherford, Accident and Emergency Department, Royal Victoria Hospital, Grosvenor Road, Belfast, BT12 6BA, Northern Ireland 


\section{PATIENTS AND METHODS}

Five hundred and six patients entered the study (279 male and 227 female). Mean age in 3 the series was 35 years with a range of 13-82 years. Details of surgical procedures are? shown in the table. During a three year period all out-patient minor surgery in the $\overrightarrow{\vec{\omega}}$ emergency department was carried out in one theatre, clean cases preceding the potentially infected patients. On a day when there were both clean and septic conditions for operation, the clean cases were taken first, followed by the septic cases. The theatre $\frac{\bar{\sigma}}{\vec{\sigma}}$ was standard with a Davidson air handling filter unit with an air flow rate of $39.63 \mathrm{~m}^{3}$ perळ minute and 20 air changes per hour.

This study surveys, prospectively, the number of wound infections which occurred in $\overrightarrow{0}$ the surgically clean conditions. Patients and surgeons changed into theatre garments and the surgeon carried out a standard surgical scrub. The operator was masked, gowned and $\stackrel{\omega}{\sigma}$ gloved in the normal fashion. Skin was prepared with Savlon and Hibitane. Haemostasis $\stackrel{\mathbb{D}}{3}$ was carefully secured and all incisions were sutured with monofilament nylon. Sutures were left for a specified time depending on the site of the operation. Between operations, $\vec{\sim}$ surfaces of instrument trolleys and operating table were swabbed with chlorhexidine. Theatre floor and walls were swabbed down nightly. If a clean case presented after $\stackrel{5}{5}$

operating on septic cases, a $2 \mathrm{~h}$ interval was allowed before operating.
All wounds were inspected at the time of suture removal and if pus or wound dehiscence $\frac{\mathrm{m}}{3}$ was present the wound was deemed severely infected. If there was redness and/or $a^{\supset}$ serous discharge this was considered mildly infected.

Information was stored and retrieved on a card system. No prophylactic antibiotigess ${ }^{+}$ were used in the study.

\section{RESULTS}

Of the original 506 patients, 482 returned to the Department for suture removal. Letters were sent to the remaining patients and further information was obtained in nine (eight healed, one infected). Fifteen patients remained in the series with no information on their 3 wound healing. Of the 491 patients for whom information was obtained, $450\left(91 \cdot 6^{\circ}{ }_{0}\right) \dot{0}$ achieved primary healing of their wounds without infection. Thirty patients $(6 \cdot 1 \%)$ developed redness or a mild serous discharge; three $(0.6 \%)$ developed wound haematomas and eight patients $(1 \cdot 6 \%)$ had severely infected wounds with a purulent discharge.

Analysis of the operations in which sepsis occurred revealed a higher rate for excision of ganglion than in other procedures (Table 1 ). Some $3.8 \%$ were severely infected and a comparison among the first four procedures of Table 1 (excluding haematoma) just failed ${ }^{\circ}$ to reach statistical significance $\left(\mathrm{x}^{2}=12,29 ; \mathrm{df}=6 ; \mathrm{p}=0 \cdot 05\right)$. Infection rates (Table 2) were analysed with respect to the major sites of surgery (head, arms-hand, leg-foot). The incidence of sepsis was significantly higher in operations performed on the lower limb $\left(\mathrm{x}^{2}=19 \cdot 60 ; \mathrm{df}=4 ; \mathrm{p}=0 \cdot 001\right)$. Severe sepsis rates in head and upper limb surgery were low $(1.7 \%$ and $1.8 \%$ respectively).

During the period of this study, 3070 septic operations were performed in the same 
Table 1 Operations

\begin{tabular}{lcccc}
\hline \multicolumn{1}{c}{ Procedure } & Healed & $\begin{array}{c}\text { Purulent } \\
\text { Discharge }\end{array}$ & $\begin{array}{c}\text { Serous } \\
\text { Discharge }\end{array}$ & Haematoma \\
\hline Excision of skin lesions & 123 & 1 & 6 & - \\
Excision of sebaceous cyst & 122 & 2 & 2 & 1 \\
Excision of ganglia & 91 & 4 & 10 & - \\
Removal of foreign body & 68 & 1 & 7 & 1 \\
Tendon repair & 22 & - & 3 & - \\
Excision of lipoma & 6 & - & 1 & - \\
Release of trigger finger & 5 & - & - & - \\
Muscle biopsy & 3 & - & - & - \\
Carpal tunnel release & 3 & - & - & - \\
Excision of breast lump & 2 & - & - & 3 \\
Excision of lymph node & 2 & - & - & \\
Excision of fibroma & 2 & 8 & 30 & - \\
Temporal artery biopsy & 1 & & & - \\
TOTAL & 450 & & - & \\
\hline
\end{tabular}

Table 2 Site of operation

\begin{tabular}{|c|c|c|c|c|}
\hline Site & Healed & $\begin{array}{l}\text { Purulent } \\
\text { Discharge }\end{array}$ & $\begin{array}{c}\text { Serous } \\
\text { Discharge }\end{array}$ & Haematoma \\
\hline Head & 117 & 2 & - & 1 \\
\hline Neck & 36 & - & 2 & - \\
\hline Trunk & 44 & - & 4 & - \\
\hline Arms/Hand & 201 & 4 & 15 & 1 \\
\hline Thighs & 8 & - & - & - \\
\hline Buttocks & 1 & - & - & - \\
\hline Groin & 0 & - & - & - \\
\hline Leg/Foot & 43 & 2 & 9 & 1 \\
\hline TOTAL & 450 & 8 & 30 & 3 \\
\hline
\end{tabular}

Table 3 Distribution of septic conditions operated on

Ingrowing toe-nail

Paronychia, pulp abscess and other finger/toe sepsis

Abscess, hand, arm, foot and leg

Abscess or infected cyst, face, head, neck

Abscess in axilla

Pilonidal abscess

Abscess chest, abdomen, back, groins, genitalia

Breast abscess

Other septic conditions 
theatre. Table 3 shows the types and distribution of septic conditions on which operations were performed.

\section{DISCUSSION}

Since 1867 when Lister published his series of articles (Lister, 1867a,b), surgeons have $\frac{\frac{5}{\frac{5}{5}}}{\frac{\rho}{6}}$ strived to decrease infection rates with varying degrees of success (Kocher, $1899 ; \stackrel{\circ}{\circ}$ Robertson, 1958; Polk, 1978). As part of this policy the concept of separate septic ando clean theatres for emergency departments was conceived. However, using the same $\overrightarrow{0}$ theatre for both clean and dirty cases we have achieved a severe infection rate of only $\vec{\omega}$ $1.6 \%$ which is approaching an acceptable incidence in wounds which are small and which cause little systemic upset.

In modern operating theatres we aim to achieve aseptic conditions. However, unless:very special arrangements are made, a certain number of organisms fall into the wound $\overrightarrow{i v}$ during the operation. The number of organisms depends on the amount of conversation, the efficiency of the ventilation system, the area of tissue exposed during operation and ${ }_{-}^{\mathrm{P}}$ the length of time taken (Charnley, 1964a,b). Whether inflammation occurs depends also on the ability of the tissues to withstand and overcome infection. In minor operations of the kind included in this series the time and the area are both small. There are two factors ${ }_{3}^{3}$ which would militate against a healthy response of the tissues. The first is poor blogd supply and this is reflected in the higher rates of sepsis for lower limb procedures. T Tene second is the presence of haematoma. We suspect that in many of the cases, both of mifodo and severe sepsis, a small haematoma was present. This is especially likely after the removal of ganglion. It is well known that drains may increase infection (Magee et al., 1976). However, it is possible that in conditions such as ganglion, where there is a high $\stackrel{\circ}{\circ}$ risk of haematoma after operations, a small vacuum drain for 24 hours following surgery $\overrightarrow{\vec{O}}$ might decrease both haematoma formation and sepsis.

The actual operations performed reflect the practice of one accident and emergency department. In the USA, emergency physicians are trained for resuscitation and the assessment and disposal of acute patients arriving at hospital. No surgery is done and] therefore there is not the same problem.

In the UK many of the consultants originally appointed to accident and emergency departments had previously worked as surgeons. They naturally were glad to treat abscesses and other acute surgical conditions which did not need hospital admission. $\bigcirc$ Even in the USA the suturing of small wounds is a function of emergency departments. In the UK the application of small skin grafts to wounds and burns, finger amputations and the suturing of extensor tendons are often performed by accident and emergencyN staff. Ganglia are frequently diagnosed in the accident and emergency department in patients presenting with sore wrists. Sebaceous cysts and small skin lesions may present either at accident and emergency departments or in the dermatology clinics. If staff and $d_{\sigma}^{\omega}$ operating facilities are available, there are advantages in patients being dealt with by a single department rather than being referred. The accident and emergency department is $\bar{\varnothing}$ one where being helpful and obliging to one's colleagues in other specialities yields? important reciprocal co-operation. 
Our results show that some clean procedures, noticeably excision of sebaceous cysts and simple skin lesions, can be performed in an operating theatre which also accommodates operations on many septic conditions. The one condition where the present results may not be acceptable is the excision of ganglia. We know of no evidence that results are better in theatres which exclude septic conditions. Improved technique to prevent haematoma formation may achieve acceptable results.

We do not wish to insist that our own particular operation lists should be compulsory for all departments. We would feel that the case for operating not only on septic conditions, but on some clean conditions is strong. While the exact nature of the clean operations may differ, they are likely to be approximately of the same extent and complexity as the procedures in our series. Our sepsis rate should be relevant to any operating list containing approximately similar material.

In conclusion we feel in future planning of emergency departments which contemplate our kind of minor surgery there is little need for separate clean and septic theatres. The ensuing financial saving should be considerable.

Further work is required to determine if equally low sepsis rates can be obtained for this kind of minor surgery carried out in treatment rooms.

\section{ACKNOWLEDGEMENTS}

Our thanks are due to the nursing and medical staff of the Accident and Emergency Department, Royal Victoria Hospital, for assistance in the study; to Miss Diana Dunlop for clerical assistance; Miss S. Campbell for typing the manuscript and to $\mathrm{Mr} \mathrm{G}$. MacKenzie for statistical analysis.

\section{REFERENCES}

Charnley J. (1964a) A sterile air operating theatre enclosure. British fournal of Surgery 51, $195-202$.

Charnley J. (1964b) A clean air operating enclosure. British fournal of Surgery 51, 202-5.

Cruse P. J. E. (1973) A five year prospective study of 23649 surgical wounds. Archives of Surgery 107, $206-10$.

Davis N. C., Cohen J. \& Rao A. (1973) The incidence of surgical wound infections: a prospective study of 20822 operations. Australian and New Zealand fournal of Surgery 43, 75-80.

Kocher T. (1899) On some conditions of healing by first intention with special reference to disinfection of the hands. Transactions of the American Surgical Association 17, 116-51.

Leissner K. H. (1976) Post-operative wound infection in 32000 clean operations. Acta chirurgica Scandanavica 142, 433-9.

Lister J. (1867a) New method of treating compound fracture, abscess, etc. Lancet i, 387-9.

Lister J. (1867b) New method of treating compound fracture, abscess, etc. Lancet ii, 668-9.

Ljungqvist U. \& Lund M. D. (1964) Wound sepsis after clean operations. Lancet ii, 1095-7.

Magee C., Rodheaver G. T., Golden G. T., Fox J., Edgerton M. T. \& Edlick R. F. (1976) Potentiation of wound infection by surgical drains. American fournal of Surgery 131, 547-9.

Polk H. C. (1978) Prevention of surgical wound infection. Annals of Internal Medicine 89, 770-3.

Purssey B. S. (1970) The use of aerosol antibiotic in minor surgery. Medical fournal of Australia 20, 989-92.

Robertson H. R. (1958) Wound infection. Annals of the Royal College of Surgeons of England 23, $141-54$. 